\title{
The Mechanism of Action of Adenine in Red Cell Preservation *
}

\author{
Yoshiki Sugita $\dagger$ and ERnest R. Simon $\ddagger$ \\ (From the Department of Medicine, University of Washington School of Medicine, the King \\ County Central Blood Bank, Seattle, Wash.; the Department of Medicine, Uni- \\ versity of New Mexico School of Medicine, and the Bernalillo County- \\ Indian Hospital, Albuquerque, N. M.)
}

Nakao and his associates have demonstrated that when blood, which had previously been stored at $4^{\circ} \mathrm{C}$ for 8 to 10 weeks in acid-citratedextrose (ACD), was subsequently incubated at $37^{\circ} \mathrm{C}$ with both adenine and inosine, regeneration of ATP and restoration of post-transfusion viability took place (1-3). ATP regeneration did not occur when the incubation medium contained either adenine or inosine alone. Moreover, supplementation of the ACD preservative with both adenine and inosine at the beginning of storage resulted in better maintenance of ATP and posttransfusion viability than in samples stored with inosine alone or not supplemented at all (3-5).

Although these studies indicated that both inosine and adenine were necessary for rejuvenation of long-stored erythrocytes, it seemed possible that adenine could act without inosine in preventing loss of red cell viability when it was present from the beginning of storage, since at that time, unlike later in storage, glucose utilization for energy production is still intact. Moreover, eliminating inosine would have the further advantage of avoiding toxicity from uric acid overload in the recipient. Accordingly, we investigated the

* Submitted for publication August 17, 1964 ; accepted December 21, 1964.

This work was supported in part by research contract DA-49-193-MD-2333 from the office of the Surgeon General, Department of the Army, and research grant AM 08131-01 HEM from the National Institute of Arthritis and Metabolic Diseases.

Part of this work was presented at the Tenth International Congress of Blood Transfusion, Stockholm, September 1964.

$\dagger$ Department of Physiological Chemistry and Nutrition, Faculty of Medicine, University of Tokyo, Tokyo, Japan.

$\ddagger$ Send requests for reprints to: Dr. Ernest R. Simon, Department of Medicine, University of New Mexico School of Medicine, Albuquerque, N. M. effect of supplementing the ACD preservative with adenine alone from the beginning of storage and showed that small amounts of adenine, without nucleoside, preserve satisfactory viability of stored erythrocytes for at least 5 weeks. Adenine also maintained higher ATP levels throughout the 6-week storage period and better preservation of erythrocyte glycolytic capacity, measured at the end of the storage period, than in control cells kept in ACD. Gluose consumption and lactate formation throughout the storage period were little affected with optimal adenine supplements despite the maintenance of higher ATP levels $(6,7)$.

The present studies were undertaken to elucidate the mechanisms whereby these effects were achieved. The influence of adenine supplementation after 2 weeks of refrigerated storage was also investigated to determine whether such delayed addition would be as effective, or perhaps even more effective, in maintaining adenine nucleotide concentrations, than supplementation at the outset.

\section{Methods}

Materials. Adenine sulfate (lot no. A89-70), ${ }^{1}$ adenine$8-C^{14}, 2$ Dowex- $1 \times 10$ chloride (200 to 400 mesh), ${ }^{3}$ cation exchange resin AG-50W-H+ $\times 2$ (50 to 100 mesh), 4 terphenyl and 1,4-bis-2-(5-phenyloxazolyl)-benzene (POPOP), 5 Tween 80 and Span 80,6 and Thixcin? were obtained commercially.

The paper radiochromatograph of the adenine-8- $\mathrm{C}^{14}$ supplied by the manufacturer revealed a single peak [n-butanol saturated with water: $\mathrm{NH}_{4} \mathrm{OH}$ (4:1, vol/

1 Sigma Chemical Co., St. Louis, Mo.

2 New England Nuclear Corp., Boston, Mass.

${ }^{3}$ J. T. Baker Chemical Co., Phillipsburg, N. J.

$\checkmark$ Bio-Rad Laboratories, Richmond, Calif.

5 Packard Instrument Co., La Grange, Ill.

- Atlas Powder Co., Wilmington, Del.

7 Baker Castor Oil Co., Los Angeles, Calif. 
vol)]. Likewise, in our radiochromatography, more than $99.7 \%$ of the radioactivity was associated with the adenine peak [isobutyric acid: $1 \mathrm{M} \mathrm{NH}_{4} \mathrm{OH}: 0.1 \mathrm{M}$ disodium EDTA $(100: 60: 1.6)]$.

The adenine supplements were prepared in $0.15 \mathrm{M} \mathrm{NaCl}$ as follows: For the addition of trace amounts, adenine$8-C^{14}$ was dissolved to a concentration of $0.5 \mu$ mole and $0.75 \mu \mathrm{c}$ per $\mathrm{ml}$ (experiment 1 ) and $0.78 \mu$ mole and $2.5 \mu \mathrm{c}$ per $\mathrm{ml}$ (experiment 2). For larger supplements, adenine$8-C^{14}$ and carrier adenine sulfate were dissolved to a final adenine concentration of $20 \mu$ moles and $1 \mu \mathrm{c}$ per $\mathrm{ml}$ (experiment 1); the corresponding values for experiment 2 were $20 \mu$ moles and $3.5 \mu \mathrm{c}$ per $\mathrm{ml}$. For experiments 3 and 4 , solutions of adenine sulfate containing $20 \mu$ moles per $\mathrm{ml}$ were used. The solutions were sterilized through Millipore ${ }^{8}$ filters, and their concentration of adenine was calculated as described previously (6).

Design of experiments. For experiments 1 and 2, 480 $\mathrm{ml}$ of blood from healthy donors was drawn into plastic bags containing $72 \mathrm{ml}$ of ACD (National Institutes of Health, formula A) and each unit divided into three smaller bags. ${ }^{9}$ Immediately thereafter, one bag was supplemented with a trace amount of adenine- $\mathrm{C}^{14}$ to give a final adenine concentration of $0.02 \mu$ mole per ml ACDblood, and another received $0.6 \mu$ mole adenine- $C^{14}$ per $\mathrm{ml}$ ACD-blood. The third bag was supplemented with 0.6 $\mu$ mole adenine- $\mathrm{C}^{14}$ per $\mathrm{ml}$ ACD-blood after 2 weeks of storage. The blood-filled bags were stored at $4^{\circ} \mathrm{C}$ and portions removed for analysis at intervals up to 6 weeks. Experiments 3 and 4 were similar except that nonradioactive adenine supplements were used. Experiments 1 and 2 were studied consecutively, 3 and 4 concurrently.

Separation of nucleotides, nucleosides, purines, and 2,3diphosphoglycerate $(2,3-D P G)$. Sixteen-ml samples of whole blood and 8-ml portions of plasma were extracted with 2 vol of cold $0.6 \mathrm{~N}$ perchloric acid (PCA) and centrifuged at $4^{\circ} \mathrm{C}$. The precipitates were re-extracted once with $15 \mathrm{ml} 0.6 \mathrm{~N}$ PCA. The combined supernatant solutions were brought to $\mathrm{pH} 9$ with $20 \% \mathrm{KOH}$, centrifuged to remove the precipitated salt, and then applied to Dowex-1-formate columns, $1 \times 16 \mathrm{~cm}$. Unknown ultraviolet absorbing materials and adenosine, if any, were eluted with $100 \mathrm{ml}$ of water. Next, adenine, inosine, hypoxanthine, and xanthine were eluted but not resolved with $300 \mathrm{ml} 0.005 \mathrm{~N}$ formic acid. Uric acid was eluted with $250 \mathrm{ml}$ of $0.05 \mathrm{~N}$ formic acid. After the removal of these purines, nucleosides, and uric acid, the separation of nucleotides and 2,3-DPG was carried out with gradually increasing concentrations of formate as described by Hurlbert, Schmitz, Brumm, and Potter (8). The water eluates from the Dowex-1-formate columns were applied to AG-50W-H $\mathrm{H}^{+}$columns, $0.9 \times 12 \mathrm{~cm}$, washed with $100 \mathrm{ml}$ of $0.1 \mathrm{~N} \mathrm{HCl}$, and eluted with 200 $\mathrm{ml}$ of $0.5 \mathrm{~N} \mathrm{HCl}$ to recover adenosine, if any. To separate the purines and inosine, the $0.005 \mathrm{~N}$ formic acid

\footnotetext{
8 Millipore Filter Corp, Bedford, Mass.

${ }^{9}$ Lot no. FS 0555B, Cutter Laboratories, Berkeley, Calif.
}

eluates were also applied to AG-50W-H+ $\mathrm{H}^{+}$columns, and xanthine and inosine, if any, were eluted with $100 \mathrm{ml}$ of $0.1 \mathrm{~N} \mathrm{HCl}$, hypoxanthine with $200 \mathrm{ml}$ of $0.3 \mathrm{~N} \mathrm{HCl}$, and adenine with $250 \mathrm{ml}$ of $0.8 \mathrm{~N} \mathrm{HCl}$. The xanthine and inosine eluates were evaporated to dryness to remove $\mathrm{HCl}$, redissolved in $10 \mathrm{ml}$ of distilled water, and separated on Dowex-1-formate columns with $250 \mathrm{ml}$ of $0.005 \mathrm{~N}$ formic acid. The Dowex-1-formate columns were eluted at $40 \mathrm{ml}$ per hour, the $\mathrm{AG}-50 \mathrm{~W}-\mathrm{H}^{+}$columns at $150 \mathrm{ml}$ per hour. The eluates from each column were collected in $10-\mathrm{ml}$ fractions, and the optical density of each fraction was measured at $260 \mathrm{~m} \mu$ with a Beckman model DU spectrophotometer. In addition, fractions eluted with water or $0.005 \mathrm{~N}$ formic acid from Dowex-1formate columns and all eluates from $\mathrm{AG}-50-\mathrm{H}^{+}$columns were read at $250 \mathrm{~m} \mu$. The peaks were identified from their ultraviolet absorbing spectra (9) by a Beckman model DK spectrophotometer and by their phosphate (10) and ribose (11) content. 2,3-DPG was quantified by phosphate assay. The over-all column recoveries of adenine, hypoxanthine, adenosine, and inosine were 96 , $95.5,100$ to 102 , and 99 to $100 \%$, respectively. In experiment 2, ATP was also measured enzymatically by the coupled reaction 3-phosphoglycerate kinase-glyceraldehyde-3-phosphate dehydrogenase (12) adapted for red cells by using 2 vol of cold $0.6 \mathrm{~N} \mathrm{PCA}$ to 1 vol of blood for deproteinization. ${ }^{10}$ The enzymatic ATP values were $6.7 \pm 5.7 \%$ lower than those obtained by column chromatography on the same filtrate. In experiments 3 and 4, ATP was measured enzymatically only.

Concentrations of metabolites are expressed as micromoles per gram hemoglobin.

Liquid scintillation counting of radioactivity in aqueous samples. A thyxotropic gel (14) was prepared by adding to $250 \mathrm{ml}$ of cold toluene, $750 \mathrm{mg}$ terphenyl, $7.5 \mathrm{mg}$ POPOP, $2 \mathrm{ml}$ emulsifier (1 part Tween 80: 9 parts Span 80 ), $2.5 \mathrm{ml}$ glycerol, and $6.25 \mathrm{~g}$ Thyxcin. The mixture was homogenized in a high speed blender, and 15$\mathrm{ml}$ quantities were transferred to counting vials. Fivetenth-ml samples from the eluate fractions were pipetted into the counting vials, shaken with the gel, counted in a Packard Tri-Carb liquid scintillation spectrometer, and compared with standards containing adenine- $\mathrm{C}^{\mathbf{1 4}}$ and concentrations of acids and salt comparable to those of the corresponding eluates. Counting efficiency varied from 27 to $33 \%$ with a background of about $25 \mathrm{cpm}$.

Specific radioactivity was calculated from the radioactivity and absorbancy of fractions representing the ultraviolet absorbing peaks.

Other methods. Pyruvate was estimated enzymatically with lactic dehydrogenase (15). Glucose, lactate, hemoglobin, hematocrit, and $\mathrm{pH}$ were measured as described previously (6).

${ }^{10} \mathrm{We}$ found that a $1: 1 \mathrm{PCA}$ filtrate, prepared as described in the directions, led to incomplete extraction of the ATP. A detailed evaluation of this method is in preparation (13). 
TABLE I

Purine compounds of blood after storage in ACD or ACD plus adenine*

\begin{tabular}{|c|c|c|c|c|c|c|c|c|c|c|c|}
\hline & \multicolumn{5}{|c|}{ Experiment 1} & \multicolumn{6}{|c|}{ Experiment 2} \\
\hline & \multicolumn{4}{|c|}{ Days } & \multirow[b]{2}{*}{44} & \multicolumn{6}{|c|}{ Days } \\
\hline & 1 & 9 & 16 & 30 & & 1 & 4 & 8 & 16 & 30 & 44 \\
\hline & & \multicolumn{6}{|c|}{$\mu$ moles $/ 10^{2} \mathrm{~g}$ hemoglobin } \\
\hline \multicolumn{12}{|c|}{ Control with Ad-C ${ }^{14}$ tracer } \\
\hline $\begin{array}{l}\text { Ad } \\
\text { ATP } \\
\text { ADP } \\
\text { AMP } \\
\text { IMP } \\
\text { Hx } \\
\text { AX }\end{array}$ & $\begin{array}{c}10 \\
375 \\
47.6 \\
<1.6 \\
17 \\
2.4 \\
13.3\end{array}$ & & $\begin{array}{r}<0.1 \\
260 \\
47.2 \\
13.0 \\
50.0 \\
<0.1 \\
19.7\end{array}$ & $\begin{array}{c}<0.1 \\
193 \\
49.2 \\
32.2 \\
49.6 \\
88.0 \\
16.5\end{array}$ & $\begin{array}{c}<0.1 \\
120 \\
35.2 \\
29.9 \\
50.8 \\
164 \\
26.2\end{array}$ & $\begin{array}{c}11 \text { to } 15 \\
403 \\
37.3 \\
6.4 \\
6.4 \\
1.1 \\
8.2\end{array}$ & & & $\begin{array}{l}<0.03 \\
331 \\
\\
18.2 \\
67.0 \\
<0.1 \\
15\end{array}$ & $\begin{array}{c}<0.03 \\
232 \\
72.5 \\
32.1 \\
62.2 \\
64.4 \\
19.1\end{array}$ & $\begin{array}{c}<0.03 \\
173 \\
38.2 \\
27.7 \\
49.4 \\
158 \\
>12\end{array}$ \\
\hline Total & 467 & & 390 & 429 & 426 & $473-477$ & & & & 482 & 458 \\
\hline \multicolumn{12}{|c|}{ Adenine added day 0} \\
\hline $\begin{array}{l}\text { Ad } \\
\text { ATP } \\
\text { ADP } \\
\text { AMP } \\
\text { IMP } \\
\text { Hx } \\
\text { AX }\end{array}$ & $\begin{array}{c}474 \\
378 \\
51.6 \\
2.8 \\
17 \\
3.6 \\
14.7\end{array}$ & $\begin{array}{r}345 \\
411 \\
86.4 \\
24.1 \\
26.8 \\
22.8 \\
21.2\end{array}$ & $\begin{array}{l}321 \\
356 \\
72.8 \\
25.3 \\
23.0 \\
42.8 \\
22.4\end{array}$ & $\begin{array}{c}303 \\
326 \\
72.4 \\
44.6 \\
27.9 \\
135 \\
23.4\end{array}$ & $\begin{array}{c}263 \\
263 \\
71.6 \\
43.8 \\
28.1 \\
216 \\
38.8\end{array}$ & $\begin{array}{r}435 \\
401 \\
39.3 \\
8.0 \\
8.1 \\
2.5 \\
9.1\end{array}$ & $\begin{array}{r}425 \\
412 \\
50.3 \\
9.1 \\
8.6 \\
4.3 \\
11.1\end{array}$ & $\begin{array}{r}350 \\
426 \\
56.9 \\
17.0 \\
16.7 \\
9.5 \\
12.6\end{array}$ & $\begin{array}{l}261 \\
457 \\
82.7 \\
30.7 \\
23.5 \\
37.5 \\
11.6\end{array}$ & $\begin{array}{c}243 \\
347 \\
91.6 \\
45.4 \\
17.5 \\
142 \\
24.2\end{array}$ & $\begin{array}{c}197 \\
316 \\
71.4 \\
45.2 \\
33.5 \\
223 \\
21.2\end{array}$ \\
\hline Total & 942 & 937 & 863 & 932 & 924 & 903 & 920 & 889 & 904 & 910 & 907 \\
\hline $\begin{array}{l}\text { Adenir } \\
\text { Ad } \\
\text { ATP } \\
\text { ADP } \\
\text { AMP } \\
\text { IMP } \\
\text { Hx } \\
\text { AX }\end{array}$ & d day 1 & & $\begin{array}{l}386 \\
303 \\
62.4 \\
29.6 \\
43.5 \\
10 \\
25.8\end{array}$ & $\begin{array}{c}344 \\
270 \\
69.2 \\
48.5 \\
24.4 \\
102 \\
19.7\end{array}$ & $\begin{array}{c}293 \\
214 \\
57.2 \\
43.4 \\
25.2 \\
207 \\
28.0\end{array}$ & & & & $\begin{array}{l}382 \\
380 \\
73.7 \\
28.4 \\
53.3 \\
3.7 \\
17.6\end{array}$ & $\begin{array}{l}332 \\
312 \\
80.1 \\
38.3 \\
27.6 \\
96.2 \\
19.8\end{array}$ & $\begin{array}{c}268 \\
282 \\
67.6 \\
40.6 \\
28.6 \\
170 \\
17.0\end{array}$ \\
\hline Total & & & 860 & 878 & 868 & & & & 939 & 906 & 874 \\
\hline
\end{tabular}

* ACD = acid-citrate-dextrose; Ad = adenine; ATP, ADP, and AMP = adenosine tri-, di-, and monophosphate; IMP = inosine monophosphate; $\mathrm{Hx}=$ hypoxanthine; AX = unknown adenine-containing compound (see Results). The hemoglobin concentration was $12.5 \mathrm{~g}$ per $100 \mathrm{ml}$ in experiment 1 and $11.0 \mathrm{~g}$ per $100 \mathrm{ml}$ in experiment 2.

\section{Results}

In the experiments to be described, radioactive adenine $(0.6 \mu$ mole per $\mathrm{ml})$ was added to ACDblood either at the beginning or after 2 weeks of refrigerated storage and its effect on purine metabolism and glycolysis throughout a 6-week storage period compared with ACD-blood controls, containing adenine- $\mathrm{C}^{\mathbf{1 4}}$ in trace amounts (0.02 $\mu$ mole per $\mathrm{ml})$.

The quantitative results are given in Tables I and II. Since the results of experiments 1 and 2 were similar, only experiment 2 was selected for graphic presentation.

\section{I) Purine metabolism}

A) Intracellular concentration of purine compounds. In the adenine-supplemented samples the initial adenine concentration decreased rapidly (Figure 1 and Table I). In samples supplemented at the beginning of storage, the ATP concentrations increased during the first 1 to 2 weeks reaching maximal values that were 10 and $14 \%$ higher than at the outset. Thereafter the ATP concentrations slowly declined so that by 6 weeks 70 and $79 \%$ of the initial ATP concentration were preserved compared with 32 and $43 \%$ for the ACD controls. Adenine supplementation after 2 weeks of storage also resulted in an initial increase in ATP followed by a decline; by 6 weeks, 57 and $70 \%$ of the initial ATP concentration remained.

In a second study of similar design 2 additional $U$ of blood were collected, subdivided, portions supplemented with adenine, and stored at $4^{\circ} \mathrm{C}$ (experiments 3 and 4 ). In the adenine- 


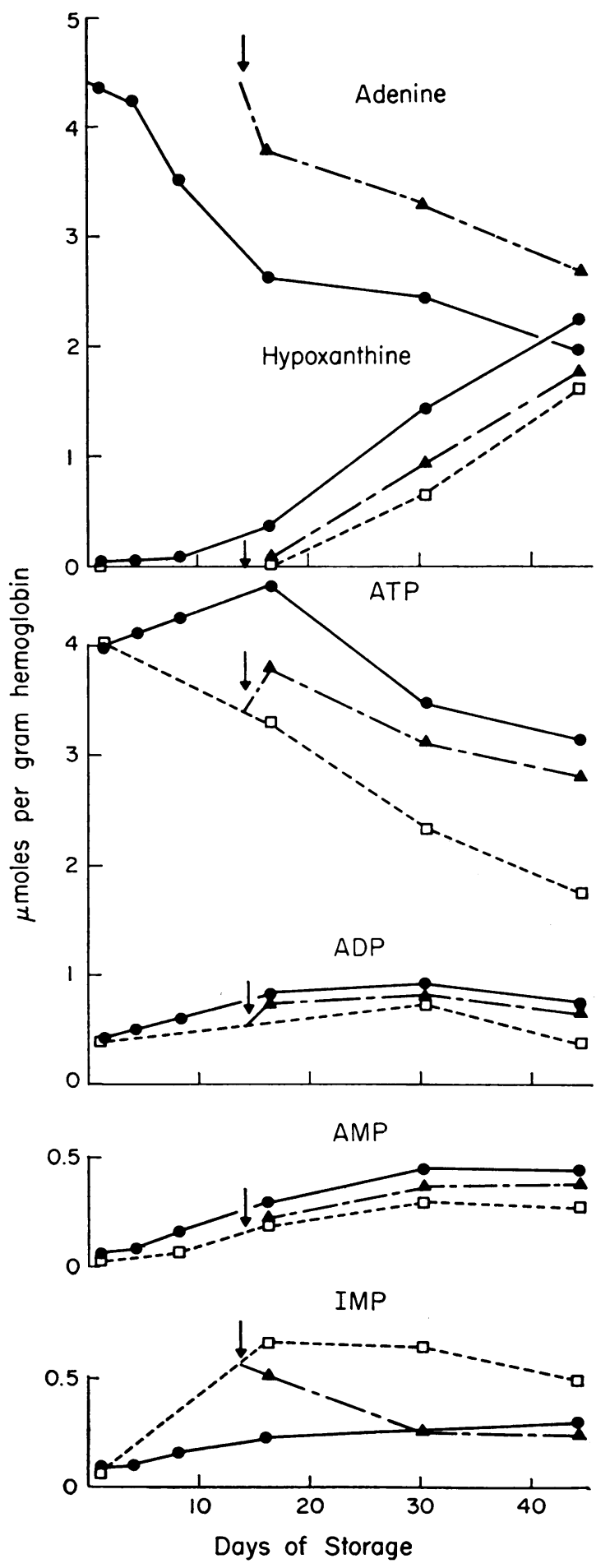

Fig. 1. Serial determinations of purine-containING COMPOUNDS IN BLOOD STORED AT $4^{\circ} \mathrm{C}$ WITH ADENINE. Experiment 2: ACD control containing tracer $(0.02$ $\mu$ mole) adenine $C^{14}, \square----\square$; $0.6 \mu$ mole of adenine per $\mathrm{ml}$ ACD-blood added on day 0 , $-0.6 \mu$ mole of supplemented samples an initial ATP increase ( 6 and $11 \%)$, measured enzymatically, preceded the subsequent decline (Figure 2). By 6 weeks, 61 and $69 \%$ of the initial ATP concentration remained with supplementation from the beginning, $75^{11}$ and $35 \%$ with addition at 2 weeks, as compared with 38 and $24 \%$ in the ACD controls.

In addition to its influence on ATP, adenine also resulted in the maintenance of higher ADP and adenosine monophosphate (AMP) levels throughout the storage period (Figure 1 and Table I); supplementation at the outset was slightly more effective in this respect than was addition after 2 weeks. In all the samples, the levels of AMP increased up to 4 weeks of storage and then remained unchanged. The behavior of ADP was slightly more variable. In experiment 1 , adenine supplementation, either at the beginning or after 2 weeks of storage, led to a rapid increase in ADP with a slight decline after 4 weeks. In experiment 2, ADP increased in all samples (more with adenine) reaching a maximum after about 4 weeks, and then declined.

The effect of adenine on total adenine nucleotide levels (AMP, ADP, and ATP) is illustrated in Figure 3. With supplementation from the beginning maximal adenine nucleotide concentrations were achieved within 1 to 2 weeks that were 22 and $27 \%$ higher than at the outset of storage. By 6 weeks, 88 and $97 \%$ of the initial total adenine nucleotide concentration were preserved with initial adenine supplementation, and 74 and $87 \%$ were preserved when it was delayed 2 weeks, compared with 43 and $53 \%$ for the controls containing adenine- $\mathrm{C}^{14}$ tracer.

During the first 2 weeks of storage, hypoxanthine accumulated only in the adenine-supplemented samples; thereafter, its rate of accumulation increased, was approximately linear with time, and was not influenced by the presence of adenine. In the ACD controls with adenine- $\mathrm{C}^{14}$ tracer, hypoxanthine was present in small amounts

11 This figure seems at variance with the remainder of the data and may represent variability of behavior of donor erythrocytes or undetected experimental error.

adenine added on day 14 (arrows), $\triangle--\Delta . \quad \mathrm{ACD}=$ acid-citrate-dextrose; ATP, ADP, and AMP = adenosine tri-, di-, and monophosphate; IMP = inosine monophosphate. 


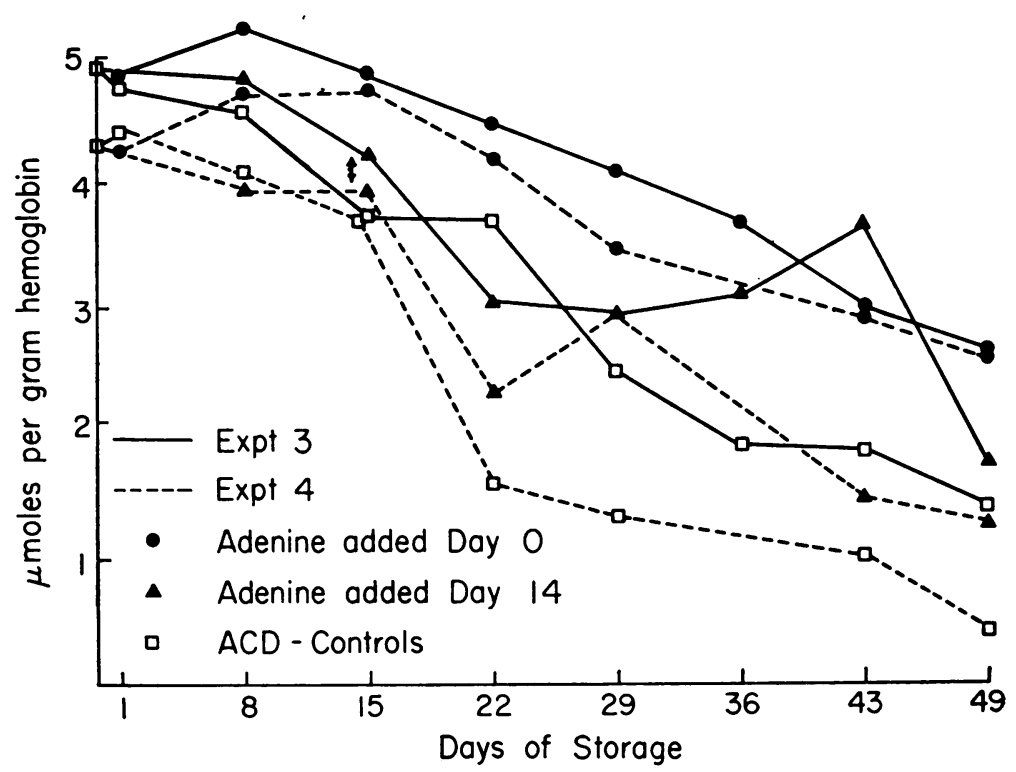

Fig. 2. Serial determinations of ATP in blood stored at $4^{\circ} \mathrm{C}$ with ADENINE. ATP was measured enzymatically. Where indicated, $0.7 \mu$ mole of adenine sulfate was added per $\mathrm{ml} \mathrm{ACD-blood.} \mathrm{The} \mathrm{hemoglobin} \mathrm{concen-}$ tration was $10.0 \mathrm{~g}$ per $100 \mathrm{ml}$ in experiment 3 and $12.9 \mathrm{~g}$ per $100 \mathrm{ml}$ in experiment 4.

on the first day of storage but was not detected in the day 16 samples.

In the $\mathrm{ACD}$ controls with adenine- $\mathrm{C}^{14}$ tracer, inosine monophosphate (IMP) had reached its maximal concentration by 2 weeks of storage. By contrast, with substrate amounts of adenine present from the beginning, the rate of increase in IMP was more gradual and reached only about one-half the concentration found in the controls. Adenine supplementation after 2 weeks of storage led to a decrease in IMP so that by 6 weeks IMP levels were slightly lower than those obtained with adenine supplementation from the beginning.

B) Specific radioactivity of purine compounds. The specific radioactivity data for experiment 2 are plotted in Figure 4; the total radioactivity recovered in the purine compounds (per gram of hemoglobin) for both experiments is given in Table II.

After the addition of adenine- $\mathrm{C}^{14}$ the specific radioactivity of AMP at first exceeded that of ADP and ATP (Figure 4). Subsequently, the specific activities of the three adenine nucleotides in each blood sample were similar to each other. In samples supplemented with $0.6 \mu$ mole of ade- nine, the specific activities of the adenine nucleotides gradually increased with time. By con-

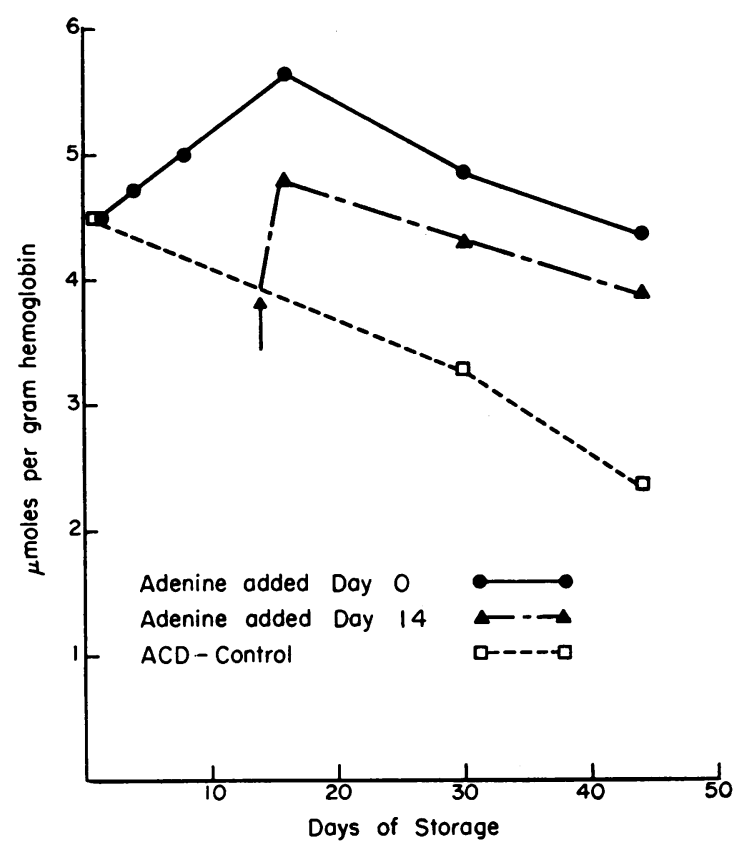

Fig. 3. SUM OF THE ADENINE NUCleotides (AMP, ADP, AND ATP) IN ACD-blood stored at $4^{\circ} \mathrm{C}$ wITH ADENINE. Experiment 2. 

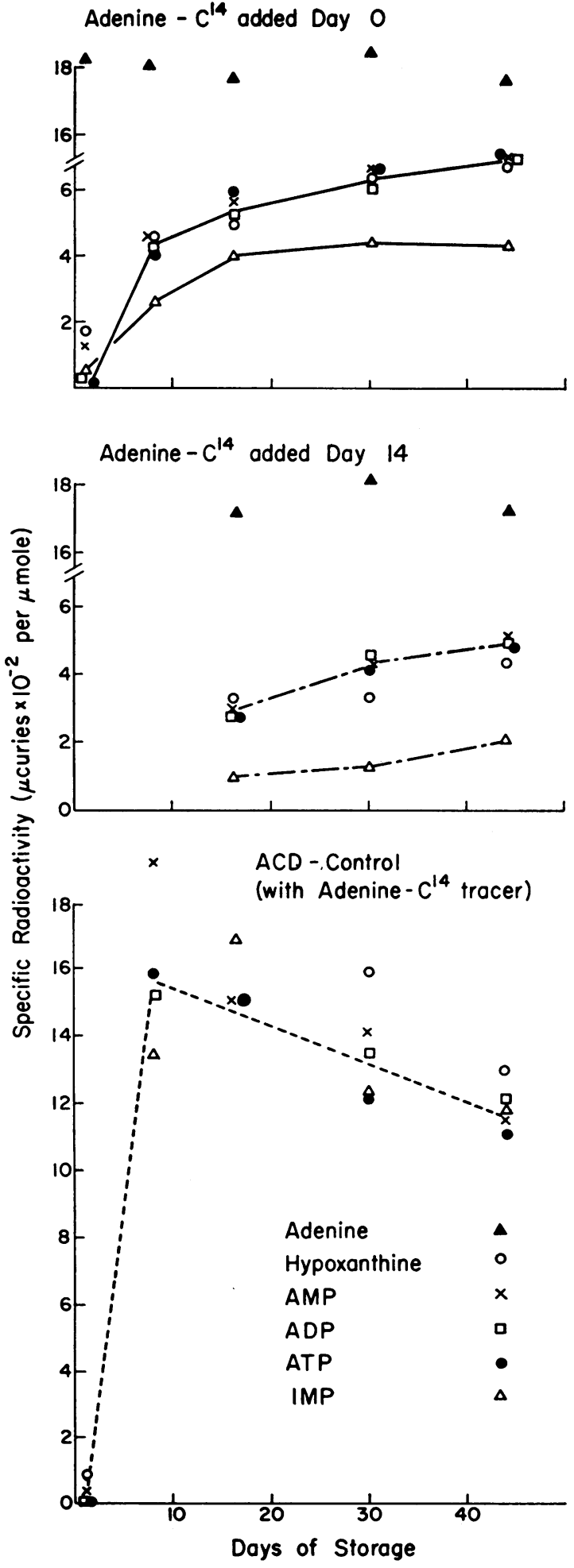

Fig. 4. SERIAL SPECIFIC RAdioactivity OF PURINECONTAINING COMPOUNDS IN BLOOD STORED AT $4^{\circ} \mathrm{C}$ WITH ADENINE-C ${ }^{14}$. Experiment 2: ACD control containing trast, in control samples containing only trace quantities of adenine $(0.02 \mu$ mole $)$ they decreased slightly after 2 weeks of storage. This was more pronounced in experiment 2 and may be due, in part, to an unexplained progressive decline in the total radioactivity recovery in this control sample (Table II).

With initial adenine supplementation the specific activities of hypoxanthine were similar to those of AMP on the first day of storage; thereafter the hypoxanthine and adenine nucleotide specific radioactivities were approximately the same. With supplementation later in storage (when hypoxanthine accumulation had already begun) the hypoxanthine specific activities were usually less than those of the adenine nucleotides.

With supplementation of substrate amounts of adenine- $\mathrm{C}^{14}$, the IMP specific activities were lower than those of the other compounds. This was more pronounced with adenine supplementation later in storage when considerable IMP accumulation had taken place. The specific activity of adenine remained constant throughout the storage period.

Neither inosine nor adenosine was detected in any of the samples throughout the 6-week storage period. The small amounts of xanthine ( 0.05 to $0.08 \mu$ mole per $g$ hemoglobin) that were present remained approximately constant and equal in all samples. Although small amounts of radioactive adenine were incorporated into as yet unidentified compounds (one such compound, AX, was eluted between ADP and ATP and is included in Tables I and II), the sum of adenine, hypoxanthine, IMP, AMP, ADP, ATP, and AX remained nearly constant in each sample throughout the storage period (Table I). The constancy of this sum has been noted previously. (16, 17).

C) Purine compounds in plasma. Of the purine-containing compounds, only adenine, hypoxanthine, xanthine, and uric acid were detected in plasma. Adenine and hypoxanthine were found

tracer $(0.02 \mu$ mole $)$ adenine- $C^{14},----$; adenine- $C^{14}(0.6$ $\mu$ mole) added on day $0, \ldots$; adenine- $C^{14}(0.6 \mu$ mole $)$ added on day $14,---$. The specific radioactivity of adenine in the supplemented samples remained constant throughout the storage period. No adenine was detected in the $A C D$ controls containing tracer adenine- $C^{14}$ after the first day of storage. 
TABLE II

Radioactivity in purine compounds of blood after storage with trace or substrate amounts of adenine-C $C^{14 *}$

\begin{tabular}{|c|c|c|c|c|c|c|c|c|c|c|}
\hline & \multicolumn{5}{|c|}{ Experiment 1} & \multicolumn{5}{|c|}{ Experiment 2} \\
\hline & \multicolumn{5}{|c|}{ Days } & \multicolumn{5}{|c|}{ Days } \\
\hline & 1 & 9 & 16 & 30 & 44 & 1 & 8 & 16 & 30 & 44 \\
\hline Contro & \multicolumn{5}{|c|}{$c p m \times 104 / g$ hemoglobin } & \multicolumn{5}{|c|}{$c p m \times 101 / g$ hemoglobin } \\
\hline $\begin{array}{l}\text { Ad } \\
\text { ATP } \\
\text { ADP } \\
\text { AMP } \\
\text { IMP } \\
\text { Hx } \\
\text { AX }\end{array}$ & \begin{tabular}{r}
\multicolumn{1}{c}{8.8} \\
8.21 \\
0.99 \\
$<0.07$ \\
0.12 \\
0.04 \\
0.09
\end{tabular} & & $\begin{array}{l}11.8 \\
2.35 \\
0.73 \\
2.36 \\
0.0 \\
0.70\end{array}$ & $\begin{array}{l}8.15 \\
2.12 \\
1.62 \\
2.16 \\
3.92 \\
0.49\end{array}$ & $\begin{array}{l}4.82 \\
1.39 \\
1.52 \\
2.02 \\
7.03 \\
0.77\end{array}$ & \multirow[t]{2}{*}{$\begin{array}{r}25.2 \text { to } \\
5.60 \\
0.54 \\
0.13 \\
\\
<0.08 \\
0.06\end{array}$} & & $\begin{array}{l}34.8 \\
1.91 \\
7.90 \\
0.0 \\
1.39\end{array}$ & $\begin{array}{c}19.5 \\
6.80 \\
3.16 \\
5.37 \\
7.15 \\
1.56\end{array}$ & $\begin{array}{r}13.3 \\
3.22 \\
2.22 \\
4.11 \\
14.30 \\
0.70\end{array}$ \\
\hline Total & 18.3 & & 17.9 & 18.4 & 17.5 & & & & 43.5 & 37.8 \\
\hline \multicolumn{11}{|c|}{ Adenine added day 0} \\
\hline $\begin{array}{l}\text { Ad } \\
\text { ATP } \\
\text { ADP } \\
\text { AMP } \\
\text { IMP } \\
\text { Hx } \\
\text { AX }\end{array}$ & $\begin{array}{c}16.8 \\
0.39 \\
0.05 \\
\\
0.02 \\
0.03 \\
0.02\end{array}$ & $\begin{array}{r}12.40 \\
4.61 \\
0.92 \\
0.26 \\
0.17 \\
0.51 \\
0.13\end{array}$ & $\begin{array}{c}11.5 \\
4.77 \\
0.97 \\
0.34 \\
0.22 \\
0.51 \\
0.20\end{array}$ & $\begin{array}{r}10.70 \\
4.86 \\
0.96 \\
0.66 \\
\\
1.86 \\
0.27\end{array}$ & $\begin{array}{l}9.41 \\
4.15 \\
1.14 \\
0.72 \\
0.30 \\
3.11 \\
0.52\end{array}$ & $\begin{array}{c}54.8 \\
0.39 \\
0.40 \\
0.06 \\
0.02 \\
0.03 \\
0.04\end{array}$ & $\begin{array}{c}43.7 \\
11.5 \\
1.67 \\
0.54 \\
0.29 \\
0.30 \\
0.31\end{array}$ & $\begin{array}{c}31.8 \\
18.6 \\
2.97 \\
1.18 \\
0.60 \\
1.27 \\
0.30\end{array}$ & $\begin{array}{c}30.8 \\
15.7 \\
3.83 \\
2.05 \\
0.53 \\
6.21 \\
0.90\end{array}$ & $\begin{array}{r}23.6 \\
15.3 \\
3.40 \\
2.17 \\
0.97 \\
10.25 \\
0.63\end{array}$ \\
\hline Total & 17.3 & 19.0 & 18.5 & 19.3 & 19.3 & 55.7 & 58.3 & 56.7 & 60.0 & 56.3 \\
\hline \multicolumn{11}{|c|}{ Adenine added day 14} \\
\hline $\begin{array}{l}\text { Ad } \\
\text { ATP } \\
\text { ADP } \\
\text { AMP } \\
\text { IMP } \\
\text { Hx } \\
\text { AX }\end{array}$ & & & $\begin{array}{c}12.5 \\
1.92 \\
0.38 \\
0.26 \\
0.08 \\
0.04 \\
0.09\end{array}$ & $\begin{array}{c}11.7 \\
2.86 \\
0.71 \\
0.51 \\
0.09 \\
0.73 \\
0.19\end{array}$ & $\begin{array}{l}9.55 \\
2.68 \\
0.64 \\
0.59 \\
0.13 \\
2.11 \\
0.28\end{array}$ & & & $\begin{array}{r}44.3 \\
7.33 \\
1.44 \\
0.57 \\
0.36 \\
0.08 \\
0.18\end{array}$ & $\begin{array}{c}41.8 \\
9.10 \\
2.58 \\
1.18 \\
0.25 \\
2.27 \\
0.52\end{array}$ & $\begin{array}{c}31.6 \\
9.59 \\
2.34 \\
1.46 \\
0.42 \\
5.34 \\
0.38\end{array}$ \\
\hline Total & & & 15.3 & 16.8 & 16.0 & & & 54.3 & 57.7 & 51.1 \\
\hline
\end{tabular}

* See Table I for abbreviations.

in higher concentrations within the cells. On the assumption that $70 \%$ of the cell volume and $93 \%$ of the plasma are water, the intracellular concentration of adenine averaged 1.8 times that of plasma; the corresponding figure for hypoxanthine was 1.5. These ratios were independent of the duration of storage. The specific activities of adenine and hypoxanthine were approximately the same inside and outside the cells. Adenine was not detected in the ACD control samples supplemented with adenine- $\mathrm{C}^{14}$ tracer after the first day of storage.

\section{II) Glycolysis}

Glycolysis was measured by glucose disappearance and lactate formation throughout the storage period. With adenine, glycolysis was slightly lower than in samples kept in ACD alone, as was reported previously (6). In all samples, $2,3-\mathrm{DPG}$ decreased rapidly and reached the lowest value by the end of 2 weeks. With adenine the rate of decrease was more rapid than in its absence (Figure 5). Pyruvate accumulation during the storage period was small.

The $\mathrm{pH}$ (measured at room temperature) was 7.12 to 7.20 at the outset of storage and declined to values between 6.74 and 6.79 after 6 weeks. Adenine supplementation did not influence these values, as was previously reported (6).

\section{Discussion}

In our previous studies $(6,7)$, we showed that supplementation of the ACD preservative with small amounts of adenine resulted in better main- 
tenance of red cell post-transfusion viability and ATP levels throughout a 6-week period of refrigerated storage. The present studies were undertaken to elucidate the mechanisms whereby these effects were achieved.

With adenine supplementation ( $0.6 \mu$ mole per $\mathrm{ml} \mathrm{ACD-blood)} \mathrm{at} \mathrm{the} \mathrm{beginning} \mathrm{of} \mathrm{storage,} \mathrm{the}$ levels of all three adenine nucleotides, ATP, $\mathrm{ADP}$, and AMP, increased up to 2 weeks of storage. In control samples with tracer adenine$\mathrm{C}^{14}$ (0.02 $\mu$ mole per $\left.\mathrm{ml}\right)$ the ATP levels decreased steadily, ADP showed little change, and AMP increased but not so much as with substrate adenine. Thereafter, the ATP levels declined in all samples, but the rate of decline was less when adenine was present. Thus, under these conditions the presence of adenine in substrate amounts led to a net synthesis of adenine nucleotides early in storage, achieving levels higher than those present in the fresh blood. Moreover, adenine maintained not only higher ATP levels but also higher adenine nucleotide levels throughout the storage period. As the adenine concentration declined, the concentration and radioactivity of the adenine nucleotides increased, indicating incorporation of adenine into the adenine nucleotides. Although the rate of adenine incorporation was more rapid early in storage, the continued gradual disappearance of adenine and the sustained rise in the adenine nucleotide specific radioactivity indicated that adenine incorporation continued throughout the storage period. These findings support the earlier observations that freshly drawn, as well as stored, human red cells are capable of incorpo-

TABLE III

Changes in purines and total adenine nucleotide concentrations between days 16 and 44 of storage with and without 0.6 umole adenine per $\mathrm{ml}$ ACD-blood

\begin{tabular}{|c|c|c|c|c|c|}
\hline$\underset{\text { ment }}{\text { Experi- }}$ & & $\Delta \stackrel{1}{A} N^{*}$ & $\Delta \stackrel{2}{\mathrm{Ad}}$ & $\Delta \stackrel{3}{\mathrm{Hx}}$ & $\begin{array}{c}4 \\
\Sigma 1,2,3\end{array}$ \\
\hline & & \multicolumn{4}{|c|}{$\mu$ moles $/ 10^{2} \mathrm{~g}$ hemoglobin } \\
\hline 1 & $\begin{array}{l}\text { Control } \\
\text { Adenine (day 0) } \\
\text { Adenine (day 14) }\end{array}$ & $\begin{array}{l}-135 \\
-75 \\
-80\end{array}$ & $\begin{array}{l}-58 \\
-93\end{array}$ & $\begin{array}{l}+164 \\
+173 \\
+197\end{array}$ & $\begin{array}{l}+29 \\
+40 \\
+24\end{array}$ \\
\hline 2 & $\begin{array}{l}\text { Control } \\
\text { Adenine (day 0) } \\
\text { Adenine (day 14) }\end{array}$ & $\begin{array}{l}-156 \dagger \\
-139 \\
-92\end{array}$ & $\begin{array}{l}-64 \\
-114\end{array}$ & $\begin{array}{l}+158 \\
+185 \\
+166\end{array}$ & $\begin{array}{l}+2 \dagger \\
-18 \\
-40\end{array}$ \\
\hline
\end{tabular}

$*$ AN $=$ Sum of ATP, ADP, and AMP

† The ADP value on day 16 was lost. These numbers represent approximations using an extrapolated value of $50 \mu$ mole : ADP per $10^{2} \mathrm{~g}$ hemoglobin for day 16 (see Table I).

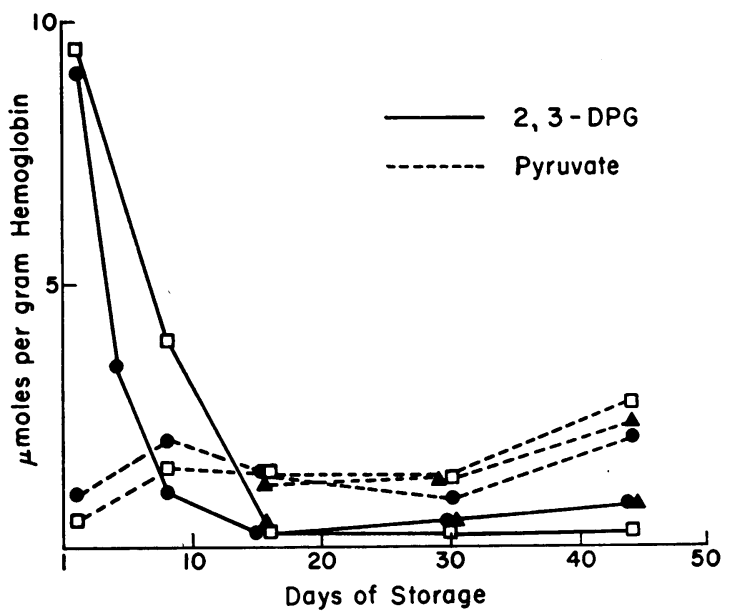

Fig. 5. Serial determinations of 2,3-DiphosphoglycERATE (2,3-DPG) AND OF PYRUVATE IN BLOOD STORED AT $4^{\circ} \mathrm{C}$ with ADENINe. Experiment 2: Same symbols as in Figure 1.

rating adenine into adenine nucleotides $(18,19)$, resulting in net adenine nucleotide synthesis (2, 20-22).

This continued slow incorporation of adenine into adenine nucleotides, rather than any inhibitory effect of adenine on adenine nucleotide breakdown, appeared responsible for the slower decline of total adenine nucleotides with adenine supplementation (Table III). Thus, between days 16 and 44 of storage, the rate of hypoxanthine accumulation was similar in all samples (column 3 ), and the amount of adenine that disappeared (column 2) approximated the difference in adenine nucleotide decline between samples stored with and without adenine (column 1). There was no breakdown of adenine nucleotides into adenine since the specific radioactivity of adenine remained constant throughout the storage period. When adenine was added to the ACD-blood after 2 weeks of storage, the changes in nucleotide and purine concentrations and in specific radioactivities were qualitatively similar, but quantitatively less than when fresh blood was supplemented with adenine.

Any mechanism for adenine incorporation into adenine nucleotides by stored red cells must explain 1) the initially higher specific radioactivities of AMP as compared with ADP and ATP, 2) the subsequent similar specific radioactivities of the three adenine nucleotides, 3) the constant 
specific radioactivity of adenine throughout the storage period, 4) the accumulation of hypoxanthine only in samples supplemented with substrate amounts of adenine during the first 2 weeks of storage, 5) the suppression of the increase in IMP with initial supplementation, and 6) the reduction in IMP concentration when adenine is added after 2 weeks.

The following reactions are consistent with these observations:

$$
\begin{gathered}
\mathrm{Ad}+\mathrm{PRPP} \longrightarrow \mathrm{AMP}+\mathrm{PP} \\
\mathrm{PP} \longrightarrow 2 \mathrm{P}_{\text {inorganic }} \\
\mathrm{AMP}+\mathrm{ATP} \longrightarrow 2 \mathrm{ADP} \\
\text { Glucose }+2 \mathrm{ADP}+2 \mathrm{P}_{\text {inorganic }} \underset{2 \text { lactate }}{\longrightarrow}+2 \mathrm{ATP} \\
\mathrm{Hx}+\mathrm{PRPP} \longrightarrow \mathrm{IMP}+\mathrm{PP}
\end{gathered}
$$

Adenine (Ad) initially reacts with 5-phosphoribosyl-1-pyrophosphate (PRPP) to form AMP and pyrophosphate (PP) via AMP-pyrophosphorylase $(20,23)$ (step 1 ). Removal of pyrophosphate via inorganic pyrophosphatase (step 2) would account for the irreversibility of step 1. The increased AMP reacts with ATP via adenylate kinase to form $\operatorname{ADP}(24,25)$ (step 3). Finally, ADP is phosphorylated to ATP via Embden-Meyerhof glycolysis (line 4). If the amount of PRPP within the red cell is limited and Ad successfully competes with hypoxanthine $(\mathrm{Hx})$ for PRPP with respect to nucleotide formation (step 5), $\mathrm{Hx}$ accumulation will begin earlier and IMP accumulation will be reduced when Ad is supplied, as was observed.

An additional mechanism for the incorporation of adenine into adenine nucleotides would involve the formation of adenosine from ribose-1-phosphate and adenine via purine nucleoside phosphorylase. Adenosine would then be phosphorylated to form AMP with an adenosine kinase. There are several objections to invoking this mechanism. First, although nucleoside phosphorylase activity utilizing adenine (measured in the direction of nucleoside formation) has been demonstrated in beef liver (26), the substrate specificity of human erythrocytic purine nucleoside phosphorylase (measured in the direction of purine formation) includes inosine and guanosine but apparently not adenosine $(27,28)$. Second, even if adenosine were formed, it is unlikely that appreciable quantities would accumulate, since blood contains a very active adenosine deaminase $(29,30)$ and, in fact, adenosine was not detected at any time in the course of the present experiments. Finally, incubation of human red cells with adenosine-8- $\mathrm{C}^{14}$ failed to produce more labeling in the adenine portion of ATP than did inosine-8- $C^{14}(22)$. Nevertheless, red cell viability is better maintained with adenosine than with inosine ( 3 ), and adenosine appears to be more effective than inosine, inosine plus adenine, or adenine alone in maintaining and regenerating ATP in stored or nucleotide-depleted cells (2, 31-38). Since adenosine, through deamination, may raise $\mathrm{pH}$ and would thus be expected to maintain hexokinase activity (39), possibly some of the aforementioned effects of adenosine on ATP maintenance and viability may be explained by this means. Until this or some other mechanism of action of adenosine is confirmed, the possibility that adenosine is an intermediate in the mechanism of action of adenine cannot be completely discarded.

Since adenine incorporation results in net adenine nucleotide synthesis and the maintenance of higher adenine nucleotide levels throughout the storage period, more energy for high-energy phosphate bond formation would appear to be required in adenine-supplemented than in control samples. The most obvious energy source is glucose, but in these experiments as well as in the ones previously reported (6), there was slightly less glucose disappearance and lactate formation in the samples supplemented with adenine. The explanation may lie in the utilization of different pathways for glucose breakdown. Thus, 1,3-diphosphoglycerate may be converted to 3-phosphoglycerate either via phosphoglycerate kinase or via 2,3-diphosphoglyceromutase and 2,3-diphosphoglycerate phosphatase-the Rapoport-Luebering cycle (40). The former reaction provides an energy generating mechanism, the latter reactions a means for excess energy dissipation. If, in the presence of adenine, a greater proportion of 1,3-diphosphoglycerate is metabolized via the phosphoglycerate kinase reaction, an increased yield of high-energy phosphate would be expected without changing glucose utilization or lactate formation. Consistent with this hypothesis are the observations in the adenine-supplemented samples of higher 
ADP levels (Figure 1 and Table II), which would be expected to favor 1,3-diphosphoglycerate metabolism via phosphoglycerate kinase (41), and the more rapid decline of 2,3-DPG (Figure 5).

These studies also provide some information about the degradative sequences of the purine compounds during the storage period. As indicated above, hypoxanthine accumulated only in the adenine-supplemented samples during the first 2 weeks of storage. Its specific activity 24 hours after adenine addition was similar to that of AMP but higher than that of ATP, ADP, or IMP. Subsequently, the specific radioactivities of the three adenine nucleotides and of hypoxanthine were similar but higher than the specific radioactivities of IMP. This suggests that a major route of AMP degradation does not pass through IMP, in contrast to previous reports $(16,18)$. Rather, AMP may be hydrolyzed to adenosine (42), then deaminated to inosine (29, $30,43,44)$, which finally undergoes phosphorolysis to hypoxanthine $(27,28,45,46)$.

Some of the hypoxanthine may then be incorporated into IMP $(16,18)$ (step 5$)$, but the specific radioactivity of the IMP will be lower than that of the other compounds due to dilution with the unlabeled IMP present at the beginning of storage (Table I) or before labeled adenine appears as labeled hypoxanthine (Figure 4).

With adenine supplementation later in storage, the reduction in IMP concentration (Figure 1) and the lowered specific radioactivities of hypoxanthine in relation to the specific radioactivities of the adenine nucleotides (Figure 4) suggest that IMP gives rise to hypoxanthine, probably by hydrolysis to inosine followed by phosphorolysis.

Neither adenosine nor inosine was detected during the storage period. Thus, the rate determining steps would appear to be the hydrolysis of AMP and IMP. Since xanthine oxidase is missing from human blood (47), the uric acid did not become radioactive, nor did its concentration change during the storage period.

In the control samples containing trace quantities of adenine, the specific radioactivities of the adenine nucleotides decreased slightly after 2 weeks of storage (Figure 4). This suggests that the adenine moiety of the nucleotides may be supplied from sources other than radioactive adenine. The synthesis of adenine from simpler units by stored blood appears most unlikely (22), and interconversion of guanine nucleotides to adenine nucleotides appears limited as well (22). In the present experiments, the adenine nucleotide fractions that are eluted from the columns just after ATP (48-52) and that identified as adenylyl-2, 3 diphosphoglyceric acid $(53,54)$ contained practically no radioactivity, and their concentrations decreased with time. It is possible that these as well as other unknown purine compounds present in small amounts entered the pool of adenine nucleotides and thus diluted their specific radioactivities. The specific radioactivity decline in experiment 2 was more marked than in experiment 1 (Figure 4), which, as was previously noted, may be due to an unexplained progressive decline in the total radioactivity recovery in this control sample (Table II).

The present studies support our previous observations (6) that red cells stored with small supplements of adenine ( 0.5 to $1.0 \mu$ mole per $\mathrm{ml}$ ACD-blood) contain more ATP after 6 weeks of refrigerated storage than do control samples stored without adenine. Recently, the effectiveness of adenine supplementation ( $0.6 \mu$ mole per $\mathrm{ml}$ ) in maintaining higher ATP and adenine nucleotide levels was confirmed by Bishop, using 48-hour incubations at $37^{\circ} \mathrm{C}(55)$, by Beutler and Duron, during storage at $4^{\circ}(56)$, and by de Verdier, Garby, Hjelm, and Högman (57), also at $4^{\circ}$, who confirmed the improved post-transfusion viability as well. However, two publications have failed to confirm the effectiveness of adenine in maintaining ATP levels. Ferber and Fischer (58) published the results of a single donor unit in which the addition of $0.5 \mu$ mole of adenine per $\mathrm{ml} \mathrm{ACD-blood} \mathrm{did} \mathrm{not} \mathrm{influence} \mathrm{the}$ decline in ATP. In the single unit studied by Shafer and Trombold (38), not only did 0.75 $\mu$ mole of adenine per $\mathrm{ml}$ ACD-blood fail to preserve significantly more ATP than did ACD alone, but only "trace" quantities of ATP remained after 6 weeks of storage, whether or not adenine was added. In the present four experiments, the concentration of ATP remaining after 6 weeks varied from 2.6 to $3.2 \mu$ moles per $\mathrm{g}$ hemoglobin (61 to $79 \%$ of the initial ATP concentration) with adenine, and 1.0 to $1.7 \mu$ moles per gram hemoglobin (24 to $43 \%$ of the initial ATP concentration) in the ACD controls. The 
minimal difference in ATP concentration between an adenine-supplemented sample and its ACD control was $1.2 \mu$ moles per $\mathrm{g}$ hemoglobin. To date, we have measured ATP after 6 weeks of refrigerated storage with and without 0.5 to $1.0 \mu$ mole of adenine (as adenine sulfate) in $23 \mathrm{U}$ of blood. Higher ATP levels in the adenine-supplemented samples were uniformly observed. The reason for the discrepant.results among these studies is not evident. The concentration of adenine and the conditions of storage appear similar. An apparently minor technical difference involved the use by Shafer and Trombold of adenine that was prepared in ACD and autoclaved, whereas in our studies, the adenine sulfate was dissolved in 0.15 $\mathrm{M} \mathrm{NaCl}$ and sterilized by filtration. This does not seem a likely explanation for the different results. Ferber and Fischer do not specify precisely how their adenine was prepared.

Our studies may permit the speculation that if means could be found to sustain the initial rapid rate of adenine incorporation, higher adenine nucleotide levels throughout the storage period could be maintained and the period of satisfactory preservation perhaps extended. Several studies have recently appeared that provide promising leads for further exploration. Beutler and Duron have shown that although the optimal $\mathrm{pH}$ of the ACD preservative was 5.0 with respect to ATP maintenance during storage at $4^{\circ}$, with adenine present in the preservative mixture, the $\mathrm{pH}$ optimum was 5.5 (56). De Verdier, Högman, Garby, and Killander have made a similar observation (59). Supplying inorganic phosphate may also produce higher ATP levels when adenine is present (60). Thus it appears likely that supplementing phosphate containing preservatives of a slightly higher $\mathrm{pH}(59,61-64)$ with adenine will give results superior to those obtained with the ACD-adenine solution used in the present study.

Finally, we must emphasize that although higher ATP or adenine nucleotide levels are associated with better post-transfusion survival under these conditions of storage $(3-6,57)$, it is premature to speculate regarding a specific level of adenine nucleotides required to give a certain per cent post-transfusion survival. There are several reasons for this: 1) factors other than the adenine nucleotide level may be of critical importance, especially if the conditions of storage are altered; 2) there remains too much interlaboratory variation both in the measurement of adenine nucleotides and of post-tranfusion survival; and, perhaps most important, 3) adenine nucleotide levels (or any other in vitro measurement) obtained after a period of storage reflect a composite both of cells that are destined for very rapid removal from the circulation and of those that survive normally or nearly so. Until methods are developed that allow separation of such nonviable from viable cells before transfusion, a quantitative relationship between intracellular adenine nucleotide levels and per cent post-transfusion survival can have only limited significance.

\section{Summary}

Adenine- $\mathrm{C}^{14}$ (0.6 $\mu$ mole per $\left.\mathrm{ml}\right)$ was added to acid-citrate-dextrose-blood at the outset or after 2 weeks of refrigerated storage, and its effect on the concentration and specific radioactivity of purines and purine nucleotides was determined throughout a 6-week storage period. With supplementation at the outset, the initial adenine concentration decreased rapidly at first, then more slowly, so that by 6 weeks, about one-half of the initial adenine remained. The adenine was incorporated into adenine nucleotides, resulting in net adenine nucleotide synthesis and values of adenosine triphosphate and of total adenine nucleotides that were about 12 and $25 \%$ higher, respectively, after 1 to 2 weeks of storage than at the outset. Thereafter, the total adenine nucleotide concentrations declined but more gradually than in the acid-citrate-dextrose controls. This slower decline could be accounted for by continued incorporation of adenine into nucleotide rather than by inhibition of nucleotide breakdown. Adenine supplementation after 2 weeks of storage was less effective in maintaining adenine nucleotide levels than was supplementation at the outset. The data support the following hypotheses : 1 ) adenine is first incorporated into adenosine monophosphate by reacting, presumably, with 5-phosphoribosyl-1-pyrophosphate, 2) inosine monophosphate is not a major intermediate in the conversion of adenosine monophosphate to hypoxanthine, and 3 ) no adenine is formed in blood during refrigerated storage. 


\section{Acknowledgments}

We wish to express our appreciation to Dr. Clement A. Finch for his helpful advice throughout this work, to Miss Karen Illman for valuable technical assistance, and to Mrs. J. Brennessel for preparing the manuscript.

\section{References}

1. Nakao, M., T. Nakao, M. Tatibana, H. Yoshikawa, and $T$. Abe. Effect of inosine and adenine on adenosine triphosphate regeneration and shape transformation in long-stored erythrocytes. Biochim. biophys. Acta (Amst.) 1959, 32, 564.

2. Nakao, M., T. Nakao, M. Tatibana, and H. Yoshikawa. Phosphorus metabolism in human erythrocyte. III. Regeneration of adenosine triphosphate in long-stored erythrocyte by incubation with inosine and adenine. J. Biochem. (Tokyo) 1960, 47, 661.

3. Nakao, K., T. Wada, T. Kamiyama, M. Nakao, and K. Nagano. A direct relationship between adenosine triphosphate-level and in vivo viability of erythrocytes. Nature (Lond.) 1962, 194, 877.

4. Nakao, M., T. Nakao, Y. Arimatsu, and H. Yoshikawa. A new preservative medium maintaining the level of adenosine triphosphate and the osmotic resistance of erythrocyte. Proc. Jap. Acad. 1960, $36,43$.

5. Wada, T., F. Takaku, K. Nakao, M. Nakao, T. Nakao, and H. Yoshikawa. Post-transfusion survival of the red blood cells stored in a medium containing adenine and inosine. Proc. Jap. Acad. 1960, 36, 618.

6. Simon, E. R., R. G. Chapman, and C. A. Finch. Adenine in red cell preservation. J. clin. Invest. 1962, 41, 351.

7. Simon, E. R. Red cell preservation: further studies with adenine. Blood 1962, 20, 485.

8. Hurlbert, R. B., H. Schmitz, A. F. Brumm, and V. R. Potter. Nucleotide metabolism. II. Chromatographic separation of acid-soluble nucleotides. J. biol. Chem. 1954, 209, 23.

9. Beaven, G. H., E. R. Holiday, and E. A. Johnson. Optical properties of nucleic acids and their components in The Nucleic Acids, Chemistry and Biology, E. Chargaff and J. N. Davidson, Eds. New York, Academic Press, 1955, vol. 1, p. 493.

10. Fiske, C. H., and Y. SubbaRow. The colorimetric determination of phosphorus. J. biol. Chem. 1925, 66, 375 .

11. Mejbaum, W. Über die Bestimmung kleiner Pentose-mengen, insbesondere in Derivaten der Adenylsäure. Hoppe-Seylers Z. physiol. Chem. 1939, 258, 117.

12. Bücher, T., and M. Schuart. Unpublished procedure; see Sammlung von Laboratoriumvorschriften, Biochemica Boehringer, C. F. Boehringer and Sons,
GmbH, Mannheim, Germany, 1957. Obtained through California Corp. for Biochemical Research, Los Angeles, Calif.

13. Bell, M., L. R. Miller, and E. R. Simon. Enzymatic determination of adenosine triphosphate in human erythrocytes. In preparation.

14. Radin, N. S. Methods of counting acids and other substances by liquid scintillation in Liquid Scintillation Counting, C. G. Bell, Jr., and F. N. Hayes, Eds. New York, Pergamon, 1958, p. 113.

15. Kubowitz, F., and O. Paul. Isolierung und Kristallisation eines Gärungsferments aus Tumoren. Biochem. Z. 1943, 314, 94.

16. Jørgenson, S. Adenine nucleotides and oxypurines in stored donor blood. Acta Pharmacol. (Kbh.) 1957, 13, 102.

17. Bishop, C. Changes in the nucleotides of stored or incubated human blood. Transfusion (Philad.) 1961, 1, 349.

18. Bishop, C. Purine metabolism in human and chicken blood, in vitro. J. biol. Chem. 1960, 235, 3228.

19. Bishop, C. Purine metabolism in human blood studied in vivo by injection of $\mathrm{C}^{14}$-adenine. $\mathrm{J}$. biol. Chem. 1961, 236, 1778.

20. Preiss, J., and P. Handler. Enzymatic synthesis of nicotinamide mononucleotide. J. biol. Chem. 1957, 225, 759.

21. Nakao, M., T. Motegi, T. Nakao, S. Yamazoe, and H. Yoshikawa. A positive feedback mechanism of adenosine triphosphate synthesis in erythrocytes. Nature (Lond.) 1961, 191, 283.

22. Lowy, B. A., M. K. Williams, and I. M. London. Enzymatic deficiencies of purine nucleotide synthesis in the human erythrocyte. J. biol. Chem. 1962, 237, 1622.

23. Kornberg, A., I. Lieberman, and E. S. Simms. Enzymatic synthesis of purine nucleotides. J. biol. Chem. 1955, 215, 417.

24. Kashket, S., and O. F. Denstedt. The metabolism of the erythrocyte. XVI. Adenylate kinase of the erythrocyte. Canad. J. Biochem. 1958, 36, 1057.

25. Tatibana, M., M. Nakao, and H. Yoshikawa. Adenylate kinase in human erythrocytes. J. Biochem. (Tokyo) 1958, 45, 1037.

26. Korn, E. D., and J. M. Buchanan. Biosynthesis of the purines. VI. Purification of liver nucleoside phosphorylase and demonstration of nucleoside synthesis from 4-amino-5-imidazolecarboxamide, adenine, and 2,6-diaminopurine. J. biol. Chem. 1955, 217, 183.

27. Gabrio, B. W., and F. M. Huennekens. The role of nucleoside phosphorylase in erythrocyte preservation. Biochim. biophys. Acta (Amst.) 1955, 18, 585.

28. Huennekens, F. M., E. Nurk, and B. W. Gabrio. Erythrocyte metabolism. I. Purine nucleoside phosphorylase. J. biol. Chem. 1956, 221, 971. 
29. Conwày, E. J., and R. Cooke. Deaminases of adenosine and adenylic acid in blood and tissues. Biochem. J. 1939, 33, 479.

30. Clarke, D. A., J. Davoll, F. S. Philips, and G. B. Brown. Enzymatic deamination and vasodepressor effects of adenosine analogs. J. Pharmacol. exp. Ther. 1952, 106, 291.

31. Mollison, P. L., and M. A. Robinson. Observations on the effects of purine nucleosides on red-cell preservation. Brit. J. Haemat. 1959, 5, 331.

32. Overgaard-Hansen, $K$. Rejuvenation of adenosine triphosphate in human erythrocytes by purine nucleosides. Acta pharmacol. (Kbh.) 1958, 14, 67.

33. Overgaard-Hansen, K., S. Jфrgensen, and E. Prætorius. Rephosphorylation produced by inosine and adenosine of adenosine monophosphate and adenosine diphosphate in human erythrocytes. Nature (Lond.) 1957, 179, 152.

34. Rubenstein, D., S. Kashket, and O. F. Denstedt. Studies on the preservation of blood. VI. The influence of adenosine and inosine on the metabolism of the erythrocyte. Canad. J. Biochem. 1958, 36, 1269.

35. Bartlett, G. R., and A. W. Shafer. Phosphorylated carbohydrate intermediates of the human erythrocyte during storage in acid citrate dextrose. II. Effect of the addition of inosine late in storage. J. clin. Invest. 1961, 40, 1185.

36. Shafer, A. W., and G. R. Bartlett. Phosphorylated carbohydrate intermediates of the human erythrocyte during storage in acid citrate dextrose. III. Effect of incubation at $37^{\circ} \mathrm{C}$ with inosine, inosine plus adenine, and adenosine after storage for 6,10 , 14, and 18 weeks. J. clin. Invest. 1962, 41, 690.

37. Crouch, S. K., and C. Bishop. The maintenance of ATP in stored blood by adenosine and inosine. Transfusion (Philad.) 1963, 3, 349.

38. Shafer, A. W., and J. S. Trombold. Phosphorylated carbohydrate intermediates of the human erythrocyte during storage in acid citrate dextrose. IV. Effect of addition of adenine, inosine, inosineadenine and adenosine at the beginning of storage. Transfusion (Philad.) 1964, 4, 120.

39. Kashket, S., D. Rubinstein, and O. F. Denstedt. Studies on the preservation of blood. V. The influence of hydrogen ion concentration on certain changes of blood during storage. Canad. J. Biochem. 1957, 35, 827.

40. Rapoport, S., and J. Luebering. An optical study of diphosphoglycerate mutase. J. biol. Chem. 1952, 196, 583.

41. Rapoport, S., F. Dietze, and G. Sauer. Quantitative Aspekte des Phosphoglyceratzyklus in roten Blutzellen. Acta biol. med. germ. 1964, 13, 693.

42. Heppel, L. A., and R. J. Hilmoe. Purification and properties of 5-nucleotidase. J. biol. Chem. 1951, 188,665 .
43. Rubinstein, D., and O. F. Denstedt. The metabolism of the erythrocyte. XIV. Metabolism of nucleosides by the erythrocyte. Canad. J. Biochem. 1956, 34, 927.

44. Rubinstein, D., S. Kashket, and O. F. Denstedt. Studies on the preservation of blood. IV. The influence of adenosine on the glycolytic activity of the erythrocyte during storage at $4^{\circ} \mathrm{C}$. Canad. J. Biochem. 1956, 34, 61.

45. Sandberg, A. A., G. R. Lee, G. E. Cartwright, and M. M. Wintrobe. Purine nucleoside phosphorylase activity of blood. I. Erythrocytes. J. clin. Invest. 1955, 34, 1823.

46. Tsuboi, K. K., and P. B. Hudson. Enzymes of the human erythrocyte. I. Purine nucleoside phosphorylase; isolation procedure. J. biol. Chem. 1957, 224, 879.

47. Gabrio, B. W., C. A. Finch, and F. M. Huennekens. Erythrocyte preservation: a topic in molecular biochemistry. Blood 1956, 11, 103.

48. Mills, G. C., and L. B. Summers. The metabolism of nucleotides and other phosphate esters in erythrocytes during in vitro incubation at $37^{\circ}$. Arch. Biochem. 1959, 84, 7.

49. Bartlett, G. R. Human red cell glycolytic intermediates. J. biol. Chem. 1959, 234, 449.

50. Bishop, C., D. M. Rankine, and J. H. Talbott. The nucleotides in normal human blood. J. biol. Chem. 1959, 234, 1233.

51. Gabrio, B .W., A. Alenty, and M. Hennessey. ATP in the erythrocyte. Fed. Proc. 1959, 18, 232.

52. Bartlett, G. R., and H. N. Barnet. Changes in the phosphate compounds of the human red blood cell during blood bank storage. J. clin. Invest. 1960, $39,56$.

53. Hashimoto, T., M. Ishii, M. Tatibana, and H. Yoshikawa. The presence of adenylyl 2,3-diphosphoglyceric acid in human and rabbit blood. J. Biochem. 1961, 50, 471.

54. Hashimoto, T., and H. Yoshikawa. Further studies on adenylyl 2,3-diphosphoglyceric acid. J. Biochem. 1963, 53, 219.

55. Bishop, C. Some in vitro effects of adenine added to stored blood. Transfusion (Philad.) 1964, 4, 265.

56. Beutler, E., and O. Duran. Effect of $\mathrm{pH}$ on preservation of red cell ATP. Transfusion (Philad.) 1965, 5, 17.

57. De Verdier, C.-H., L. Garby, M. Hjelm, and Högman. Adenine in blood preservation: posttransfusion viability and biochemical changes. Transfusion (Philad.) 1964, 4, 331.

58. Ferber, E., and H. Fischer. Untersuchungen zur verbesserten Zellkonservierung. III. Mitteilung. Die Wirkung von Purinnucleosiden und Steroiden auf die mechanische Resistenz frischer und gelagerter Erythrocyten. Klin. Wschr. 1963, 41, 427. 
59. De Verdier, C.-H., C. Högman, L. Garby, and J. Killander. Storage of human red blood cells. II. The effect of $\mathrm{pH}$ and of the addition of adenine. Acta physiol. scand. 1964, 60, 141.

60. Bishop, C. Preventing the breakdown of ATP in stored blood by the addition of phosphate. Fed. Proc. 1964, 23, 532.

61. Gibson, J. G. II, S. B. Rees, T. J. McManus, and W. A. Scheitlin. A citrate-phosphate-dextrose solution for the preservation of human blood. Amer. J. clin. Path. 1957, 28, 569.
62. Kleine, N., and H. Schmitt. Neue Gesichtspunkte und Erkenntnisse für die Lagerung von Blutkonserven. Blut 1962, 8, 145.

63. Bowman, H. S. Red cell preservation in citratephosphate-dextrose and in acid-citrate-dextrose: comparison of erythrocyte viability after 28 days refrigerated storage. Transfusion (Philad.) 1963, 3,364 .

64. Kozek, W., and C. Bishop. Comparison of blood stored in ACD and in a solution containing heparin, phosphate, glucose and adenine. Transfusion (Philad.) 1964, 4, 271. 